\title{
Automatic Summarization on Restaurants Opinion Mining
} Miss Sonal Anil Rathi", Prof. Krutika K Chhajed

Department of Computer Science \& Engineering, P. R. Pote (Patil) College of Engineering \& Management, Amravati, Maharashtra, India

\begin{abstract}
Article Info

Volume 8, Issue 4

Page Number : $30-35$

\section{Publication Issue}

July-August-2021

\section{Article History}

Accepted : 01 July 2021

Published : 05 July 2021

Innovation has been a fundamental piece of our lives. When going bent another cafe/restaurants or bistro, individuals normally use sites or applications to question close by spots and afterward select one hooked in to normal rating. Notwithstanding, the traditional rating is now and again insufficient to foresee the character of the café as individuals have alternate points of view and wishes while assessing an eatery. During this paper, an overview framework for sentiments in eatery audits is proposed. The framework may be a useful device for clients during a hurry to assist them improve decisions about the nature of a restaurant while saving their time. This is often finished via naturally and rapidly furnishing the clients with a synopsis of the sentiments within the café's/restaurants surveys. The proposed synopsis framework has been actualized during a versatile area based application with KNN Algorithm and Multi keyword search it accomplished a high convenience score.

Keywords : Automatic opinion summarization, restaurant reviews and rank, nearby restaurants lookup application-KNN, sentiment analysis, multi-keyword ranked search.
\end{abstract}

\section{INTRODUCTION}

In broad terms Opinion Mining is that the science of using text analysis to understand the drivers behind the overall public sentiment. Within the subsequent Opinion Recognition System we'll rate the restaurants by classifying and studying there reviews by using Opinion Mining, Sentiment Analysis, etc. We propose a propelled Restaurant Review System that recognizes concealed assessments within the reviews of the client and rates the Restaurants therein particular manner. The System takes input from different clients, in light of the sentiment, the system will indicate whether the posted Restaurant is suitable, terrible, or most exceedingly awful. [1]

The ever-expanding utilization of the online and online exercises (like visiting, conferencing, ticket booking, online exchanges, web-based business, webbased life interchanges, blogging, and miniaturized scale blogging, clicks streams, then forth.) drives us to urge obviate, change, load, and break down an 
immense measure of organized and unstructured information, at a quick pace, alluded to as Big Data. [2] Substances during a restaurant allude to items (for example nourishment), administrations, people (for example staff), occasions, and so on. Angles are the qualities or segments of these substances. As an example, within the audit "nourishment tasted incredible", nourishment is that the substance, and thus the taste is its angle. While thinking about the connections between various substances, a component may become an area of another element. Within the advanced time, clients depend on café audits to pick a superior eatery to eat in. Notwithstanding, perusing plenty of surveys and deciding could also be a dull procedure. During this way, it's attractive to process client audits and naturally discover rating esteems for eateries. [7] Lately, clients visit a restaurant with various goals, as an example, having gatherings and gatherings. Hence they're keen on the evaluations for various viewpoints that are identified with their goal of the visit. As an example, plenty of experts who wish to choose a restaurant for a gathering would be keen on the rating for the part of stopping. Be that because it's going to, physically experiencing client audits to pick an eatery enthusiastic to a couple of these angles is an awesome assignment. Perspective level notion investigation (or supposition mining) has been proposed as an answer to this. Here, we've done this for the foremost part centre on breaking down abstract sentences. As an example, here is an audit of a lodging. [3] "The nourishment was scrumptious, clean, and top-notch. The staff, bellmen, and servers were useful. Solicitations for extra items substance were constantly given. The warming and cooling worked well. The convenience was the only we've at any point experienced. Right now, we propose sentiment analysis frameworks which can provides a sense score to the entire survey whilst dissect the notion of every individual a neighbourhood of the Restaurant. Immediately propose an estimation examination undertaking of the dataset. Especially we've considered for the subtasks.

\section{RELATED WORK}

Being an exceptionally helpful framework, the restaurant proposal takes after the principle a neighbourhood of the supposition sifting of the surveys. Numerous recently built applications or sites are by and massive as of now getting used out of which one is exceptionally famous in San Francisco, California. It's Yelp. [8] Howl is an eatery proposal and rating framework which is during a fantastic use since it has been made. Separated then a significant organization or a framework programming numerous individuals have likewise turned the stones with regard to the Opinion Recognition framework for Restaurants. Ekaterina Pronoza, Elena Yagunova, Svetlana Volskaya, and Andrey Lyashin, have also made some efforts in making a Restaurants Information Extraction System. [1] Swant and Pai have introduced a suggestion framework that's fit computing the rating for an eatery enthusiastic to the important numerical rankings given by clients and prescribing an appropriate café for a client utilizing bunching calculations. Gupta et al. have targeting abridging café surveys by joining the notion of extremity of an audit to three fundamental viewpoints nourishment, administration, and atmosphere. [2] A relapse based because of affect discovering estimation polarities is presented by Ganu et al., which centres around the classes of nourishment, administration, value, mood, tales, and various. It distinguishes four by and massive notion extremity names (positive, negative, clash, nonpartisan) for a given sentence and doles out a minimum of 1 viewpoints in conjunction with an extremity mark for every angle. Be that because it's going to, nothing from what was just mentioned examine has targeting distinguishing rating esteems for all the progressively related parts of an eatery. In synopsis, this examination cares a couple of elevated 
level perspectives or low-level angles just, or both autonomously while performing viewpoint level assessment investigation in eatery surveys. [4] Almost no examination considers even a subset of the chain of importance of viewpoints to process organized labels offered by clients to talk thoughts on the social setting. None has targeting using the substance perspective or element connections which can be displayed as a sequence of command of viewpoints accordingly empowering feeling score count of an angle as a composite score of its sub-perspectives by performing angle level assumption investigation in café audits.

\section{METHODOLOGY OF SYSTEM}

This is the defined workflow of all the info which is collected as shown in Figure 1. The collected data is then skilled the processing part. The complete methodology is shown in figure 2 .

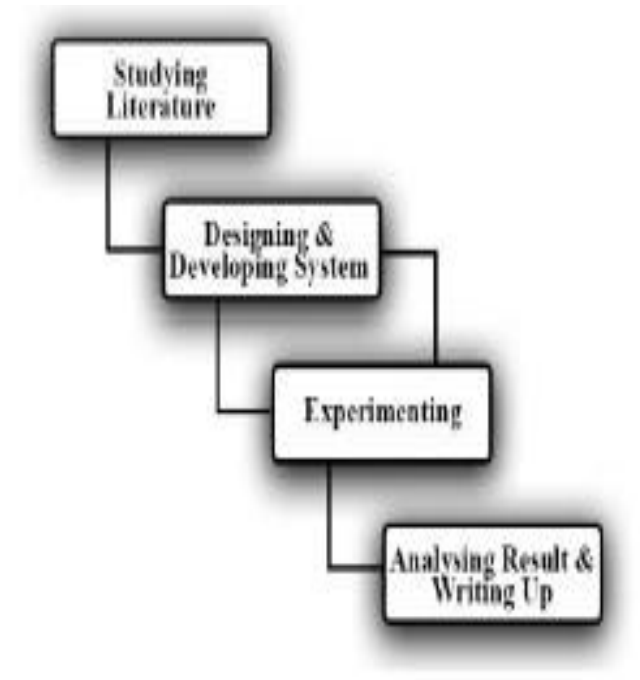

Figure 1: Methodology

\section{A. DATA COLLECTION:}

The info for the system is to be collected from online sites like Zomato. the data collected are getting to be then extracted within the files suitable for the evaluation formerly a .tsv (Tab Separated Value).

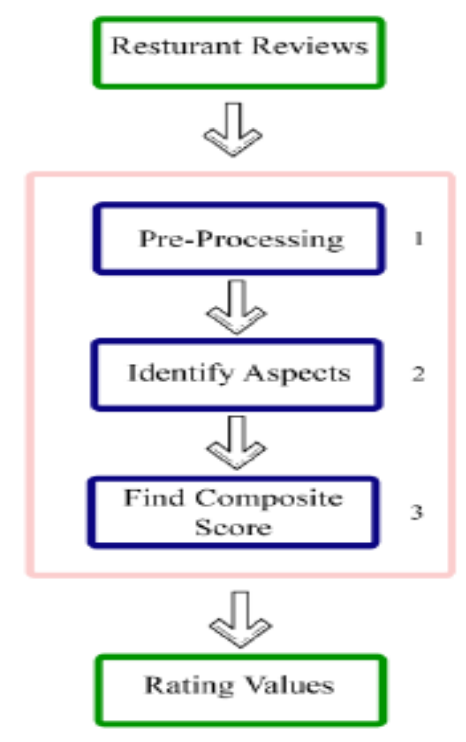

Figure 2: Workflow

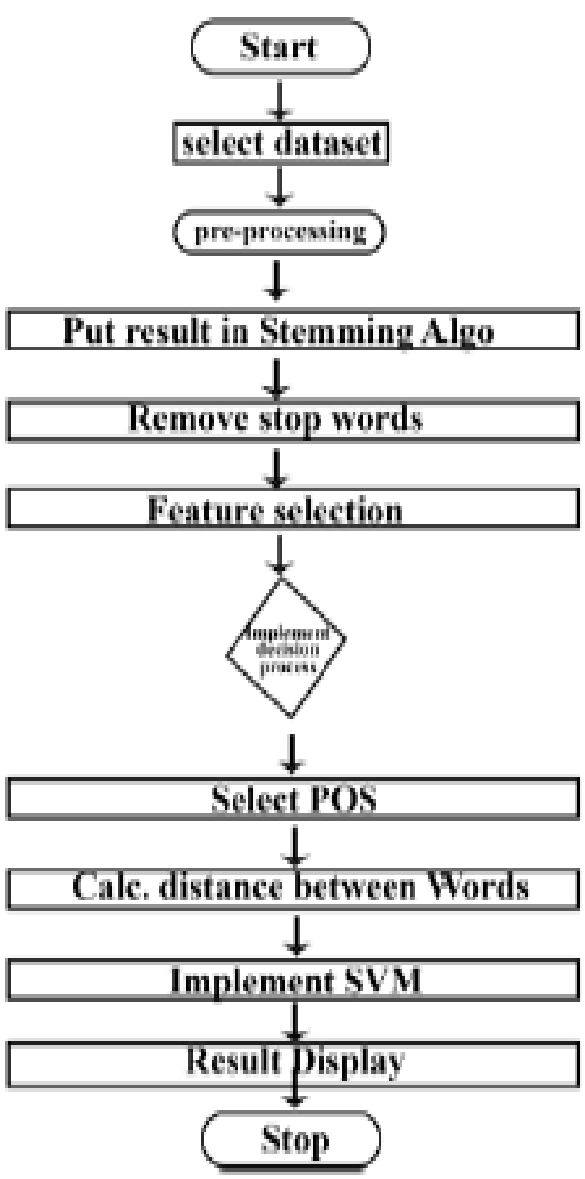

Figure 3: Data flow chart

\section{B. PROCESSING PHASE:}


During this phase, the unwanted lines and stop words are getting to be away from the data collected. [7] the data flow chart involves the entire evaluation of each step as shown in figure 3. Like removal of unnecessary words, removal of articles (which are getting to be defined in several files) and to use the stemming procedure to hunt out the related words (For eg. like, likes, liked, liking). The processing would be exhausted the next manner as shown within the figure below.

\section{REPRESENTATION PHASE:}

The System will utilize the database and may coordinate the input with the catchphrases within the database and may rank the criticism. The work of the administrator is to post the new Restaurant and includes catchphrases within the database. [10] The new Evaluation Scheme is shown in Figure 4. We use a database of sentiment based keywords alongside positivity or negativity weight in database then supported these sentiment keywords mined in user feedback is ranked. We'll majorly use the Opinion Mining Algorithms alongside the Sentiment Analysis.

The data thus evaluated are getting to be represented within the type of a graph which can act between the choice of a bar chart or a chart. Supported the filtered reviews of each person all the data will get acquainted. [6][5][11] Each of the review are getting to be assigned a composite erase of $1,2 \& 3$. According to the composite score the rating are getting to be done of all reviews and making a mean to undertake to the same for the Restaurants which all are getting to be rated within the system.

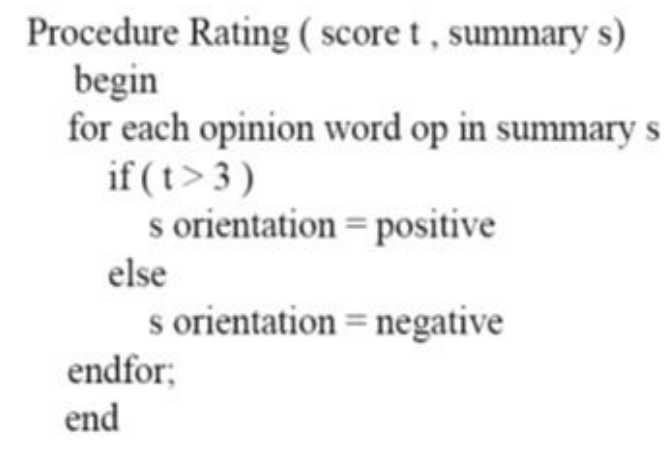

Figure 4: New Evaluation Scheme

\section{RESULT}

The reviews thus passed in evaluation will return either "Positive Review" or "Negative Review" which can be the output itself for rating a restaurant. Within the following case we've taken 1000 reviews which are scrapped from zomato of some randomly restaurants and given each of them there composite score. Consistent with composite score evaluation the subsequent output is obtained as defined. [7][8][11] Its alright seen that the outcomes from the program are moderately just like the real qualities. The output is shown in Figure 5.

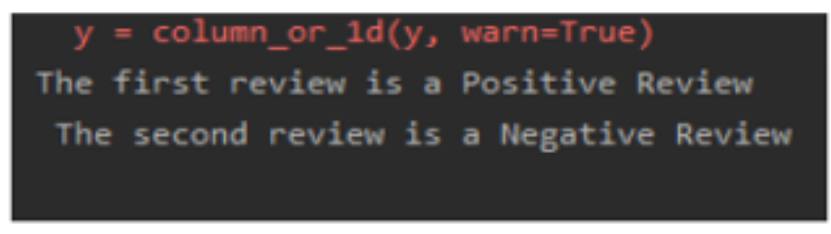

Figure 5: Review Output

\section{CONCLUSION}

This paper introduced a programmed synopsis framework for feelings in eatery/ restaurant surveys, and it was executed in an area based portable application. The application is intended to assist the clients with finding the close by eateries, bistros and restaurant with the help of $\mathrm{KNN}$, and view audit rundown for them. This application will save the client's time and exertion, since it will give slant examination to all audits and this component isn't given by some other application. 
The proposed synopsis framework gives a multiarchive assumption examination; it sums up the conclusions on the whole the surveys for an eatery. The cycle of audit rundown is introduced in detail. The last yield is the audit outline which is chiefly made out of two sections. The initial segment is the rates of positive and negative assessment words and expressions among all the assessment words and expressions that exist in the surveys of this eatery its gives proper results because of opinion mining and sentiment lexicon. This gives the client a thought regarding the difference between the positive and negative assessments in the eatery's audits. The second piece of the audit rundown is an addresses a word cloud for all the assessment words and expressions in the surveys of the café. This permits the clients to see which sentiments make a difference to them and judge the recurrence of these feelings dependent on their size. Therefore, the created survey outline is more valuable and supportive to the client than simply the normal client rating for an eatery.

\section{REFERENCES}

[1]. Ho, S.Y. and K.K.W. Ho, "The Effects of web personalization on influencing users' switching decisions to a new website," PACIS Proceedings, Paper 67, $2008 \backslash$

[2]. Thirumalai, S. and K. K. Sinhab, "Customization of the online purchase process in electronic retailing and customer satisfaction: An online field study," Journal of Operations Management, Vol. 29, No. 5:477-487, 2011.

[3]. Tam, K. Y., and, S. Y. Ho, "Understanding the impact of web personalization on user information processing and decision outcomes," Mis Quarterly, Vol.30, No. 4:865-890, 2006.

[4]. Wang, W., and I. Benbasat, "Trust In and Adoption of Online Recommendation Agents," Journal of the Association for Information Systems, Vol.6, No.3, Article 4, 2005
[5]. Xua, H., X. (Robert) Luob, and J. M. Carrolla, and M. B. Rossona, "The personalization privacy paradox: An exploratory study of decision making process for location-aware marketing," Decision Support Systems, Vol.51, No.1:42-52, 2011

[6]. Karimi, S., K. N. Papamichail, and C. P. Holland, The effect of prior knowledge and decision-making style on the online purchase decision-making process: A typology of consumer shopping behavior, Decision Support Systems, Accepted Manuscript 2015.

[7]. Ardissono, L., A. Goy, G. Petrone, and M. Segnan, "Personalization in business-tocustomer interaction," Communications of the ACM, Vol.45, No. 5: 52-53, 2002.

[8]. Shafiq, O., R. Alhajj and J. G. Rokne, "On personalizing Web search using social network analysis," Information Sciences, Vol.314, No.1:55-67, 2015

[9]. Hawalah, A. and M. Faslia, "Dynamic user profiles for web personalization," Expert Systems with Applications, Vol.42, No.5:25472569, 2015.

[10]. Pang, B. and L. Lee, "Opinion Mining and Sentiment Analysis," Foundations and Trends in Information Retrieval, Vol. 2:1-135, 2008.

[11]. Liu, B. and L. Zhang, "A survey of opinion mining and sentiment analysis," Mining Text Data, Springer US, 2012. ISBN 978-1-46143222-7

[12]. Duan, W., B. Gu, and A.B. Whinston, "Do online reviews matter? - An empirical investigation of panel data," Decision Support Systems, Vol. 45:1007-1016, 2008.

[13]. Diakopoulos, N., and D. Shamma, "Characterizing debate performance via aggregated twitter sentiment," Proceedings of the 28th international conference on Human factors in computing systems, Atlanta, Georgia, 2010. 
[14]. Bollen, J., H. Mao, and X. Zeng, "Twitter mood predicts the stock market," Journal of Computational Science, Vol.2, No.1:1-8, 2011.

[15]. Missen, M., M. Boughanem, and G. Cabanac, "Opinion mining: reviewed from word to document level," Social Network Analysis and Mining, Vol. 3, No. 1:107-125, 2013.

[16]. Esuli, A. and F. Sebastiani, "SentiWordNet: a publicly available lexical resource for opinion mining," Proceedings of the 5th conference on language resources and evaluation, pp. 417-422, 2006.

[17]. Kennedy, A. and D. Inkpen, "Sentiment classification of movie reviews using contextual valence shifters," Computing Intelligence, Vol. 22, No.2: 110-125, 2006.

[18]. Ku, L.-W., L.-Y. Li, T.-H. Wu and H.-H. Chen, "Major topic detection and its application to opinion summarization," SIGIR, 627-628, 2005.

[19]. Tang, H., S. Tan, and X. Cheng, "A survey on sentiment detection of reviews," Expert Systems with Applications: An International Journal, Vol. 36, No. 7:10760-10773, 2009.

[20]. Zhuang, L., F. Jing, and X.Y. Zhu, "Movie review mining and summarization," Proceedings of the 15th ACM international conference on Information and knowledge management, pp. 43-50, 2006.

[21]. Meng, X. and H. Wang, "Mining user reviews: from specification to summarization," Proceedings of the ACL-IJCNLP 2009 Conference Short Papers, pp. 177-180, 2009.

[22]. Chen, Y. J. and Y. M. Chen, "Acquiring Consumer Perspectives in Chinese eWOM," Journal of Information Management, Accepted, 2015

[23]. Di Marco, A. and R. Navigli, "Clustering and diversifying web search results with graphbased word sense induction," Computational Linguistics, Vol.39, No.4:1--43, 2013.

[24]. Han, J., M. Kamber, and J. Pei, "Data Mining: Concepts and Techniques," Third Edition, the
Morgan Kaufmann Series in Data Management Systems, 2011.

\section{Cite this article as :}

Miss Sonal Anil Rathi, Prof. Krutika K Chhajed, "Automatic Summarization on Restaurants Opinion Mining", International Journal of Scientific Research in Science and Technology (IJSRST), Online ISSN : 2395-602X, Print ISSN : 2395-6011, Volume 8 Issue 4, pp. 30-35, July-August 2021. Available at doi : https://doi.org/10.32628/IJSRST218414 Journal URL : https://ijsrst.com/IJSRST218414 